\title{
Sacrificial Copper Strip Sensors for Sulfur Corrosion Detection in Transformer Oils
}

\author{
M.S. Ahmad Khiar ${ }^{a, b, *}$, R.C.D. Brown ${ }^{c}$, P.L. Lewin ${ }^{a}$, \\ aThe Tony Davies High Voltage Laboratory, University of Southampton, Southampton SO17 1BJ, UK. \\ ${ }^{b}$ High Voltage Engineering Research Laboratory, Centre for Robotics and Industrial Automation, Faculty of \\ Electrical Engineering, Universiti Teknikal Malaysia Melaka (UTeM), Melaka, Malaysia. \\ 'Department of Chemistry, University of Southampton, Southampton SO17 1BJ, UK. \\ E-mail addresses: msak1g15@ soton.ac.uk, mohd.shahril@utem.edu.my (M.S. Ahmad Khiar), \\ pll@ecs.soton.ac.uk (P.L. Lewin).
}

\begin{abstract}
Existing protocols (e.g., ASTM D 1275-B standard test method) applied to detect and monitor sulfur corrosion in transformer insulating oils are imprecise as it depends on visual observation. As a solution, thin-film sacrificial copper strips are proposed as a corrosive sulfur sensor. A two-level factorial design is utilized to investigate the significant effect of area and thickness upon the sensor's transformation resistance values. Next, a regression model is developed to estimate the sensor's transformation resistance values as functions of area and thickness. The resultant outputs from the two-level factorial design revealed that area, as a variable, exhibited higher significance at $90.19 \%$, compared to either thickness or interaction between area and thickness. The proposed regression model obtained from two-level factorial design is significant in describing the trend displayed by the sensor's transformation resistance values. Finally, this paper details the clear correlation between the sensor's transformation resistance values and elemental sulfur concentration.
\end{abstract}

\section{Highlights}

1. A new test to track the progression of elemental sulfur in oils is proposed.

2. The proposed method is based on thin film sacrificial copper strips.

3. Thin film sacrificial copper strip is capable to classify corrosivity levels of oils.

4. Regression model to estimate the sensor's transformed resistance values is developed.

\section{Keywords}

Factorial design; sulfur; 4-wire measurement; corrosion sensor; thin-film copper 


\section{Introduction}

Insulating oil serves as a coolant and electrical insulator to ensure reliable operation of high voltage equipment under normal operating conditions. In oil-filled power transformers, mineral oil-based dielectric liquids are used as insulating media and are processed from refined crude petroleum. Petroleum refinement is particularly important because it transforms crude oil into oil-based products with desired physicochemical properties. These oil-based products are carefully refined to fulfil the requirements of specific applications. Although crude oil predominantly comprises of saturated hydrocarbon molecules, it contains a wide range of impurity species; in particular molecules that contain sulfur (hydrogen sulfide, elemental sulfur, mercaptans, alkyl sulfides, thiophenes), oxygen (naphthenic acids), and nitrogen (frequently encountered in asphaltenes), as well as metal species and aromatic compounds. Hence, the oil refinement process should completely remove or minimize these impurities, particularly sulfur, because corrosive elemental sulfur can react with copper and cause a specific corrosion phenomena that left unchecked will significantly reduce the operational lifetime of the transformer.

Various types of sulfur compounds exist in mineral oil; some originating from virgin oil, while others are unintentionally introduced during the manufacturing process [1]. Sulfur introduced via manufacturing processes is usually due to unsophisticated oil manufacturing technology and refining processes, as well as replenishment of additives, such as antioxidants to prolong the oxidation stability [2] of mineral oils. Sulfur can be found in the mineral oil in elemental form or in organosulfur molecules, namely thiophenes, disulfides, polysulfides, dialkyl sulfides (thioethers), and mercaptans (thiols). Each compound has its own unique reaction rate with copper, which ultimately forms copper sulfide species, as solid corrosion products or complexes, depending upon the concentration of the compounds, copper surface condition, temperature, and aging time [3]. The corrosive levels of sulfur are ranked from 
elemental sulfur $>$ mercaptans $>$ sulfides $>$ disulfides $>$ thiophenes $[3,4]$. Hence, elemental sulfur is considered as the most reactive compound with copper, followed by reactive mercaptans. Meanwhile, thiophenes are non-reactive sulfur compounds, whereas disulfides are relatively stable. Nevertheless, disulfides can degrade into benzyl mercaptans, resulting in more corrosive species [5,6].

In oil-filled power transformers, sulfur corrosion occurs primarily due to the reaction of existing corrosive sulfur compounds. This particular corrosive sulfur is known as elemental sulfur in insulating oils and copper conductors, which leads to the formation of copper sulfide [4]. For the case of insulating oil, sulfur corrosion is a function of corrosive by-products because of breakdown in stable compounds, namely dibenzyl disulfide (DBDS), which is partly responsible for copper sulfide formation [7-9]. Upon formation, it is likely that copper sulfide will deposit onto the copper surface or insulation paper that is impregnated with insulating oil, thus resulting in turn-to-turn transformer breakdown $[2,10]$.

Although the breakdown of DBDS is believed to be the main cause of copper sulfide formation, insulating oils are still found to be corrosive in the absence of DBDS [9], hence indicating that other sulfur species have the ability to induce a corrosive environment. This phenomenon is reported to be on the increase and worldwide substantial number of transformer units have failed since the beginning of this decade [11]. Passivation techniques and additives have been developed and employed to passivate the corrosive sulfur species in the insulating oils. However, these techniques lead to the generation of passivator-induced stray gassing (due to hydrogen, carbon monoxide, and carbon dioxide release) [12]. The released hydrogen in the insulating oils causes difficulties in interpreting the gases results such as dissolved gas analysis because the presence of hydrogen in the insulating oils is not only due to the effect of passivators (i.e. Irgamet ${ }^{\circledR} 39$ ) but also depends on other mechanisms such as partial discharge. 
Therefore, reliable condition monitoring tools are absolutely vital to monitor the continuous presence of corrosive sulfur species in transformer oils to avoid catastrophic transformer failure.

Initially, the detection of corrosive sulfur species is carried out by the manufacturers of insulating oils to ensure that the oils comply with the relevant international standards. Thereafter, corrosive sulfur species are detected by transformer system operators, who regularly undertake oil quality monitoring processes. To date, there are four common standard corrosion tests, as presented in Table 1. These tests rely on comparing the color of a silver or copper strip with the ASTM copper strip corrosion standard [13] (see Figure 1) to deduce the corrosivity levels of the insulating oils under assessment. Unfortunately, this method is imprecise due to visual-based observations and the fact that it is an off-line test dependent on a small sample volume compared with the total oil volume of the transformer.

Table 1. Standard test methods to determine corrosivity levels of oils.

\begin{tabular}{|c|c|c|c|c|}
\hline Method & Material & $\begin{array}{c}\text { Description } \\
\text { (Oil/Metal/Paper) }\end{array}$ & $\begin{array}{c}\text { Temperature } \\
\left({ }^{\circ} \mathrm{C}\right)\end{array}$ & $\begin{array}{c}\text { Time } \\
(\mathrm{h})\end{array}$ \\
\hline DIN 51353 & $\mathrm{Ag}$ & $100 \mathrm{~mL} / 1600 \mathrm{~mm}^{2} /-$ & 100 & 18 \\
\hline ASTM D1275A & $\mathrm{Cu}$ & $250 \mathrm{~mL} / 300 \mathrm{~mm}^{2} /-$ & 140 & 19 \\
\hline ASTM D1275B & $\mathrm{Cu}$ & $250 \mathrm{~mL} / 300 \mathrm{~mm}^{2} /-$ & 150 & 48 \\
\hline BS EN 62535 & $\mathrm{Cu}$ & $15 \mathrm{~mL} / 540 \mathrm{~mm}^{2} / 540 \mathrm{~mm}^{2}$ & 150 & 72 \\
\hline
\end{tabular}

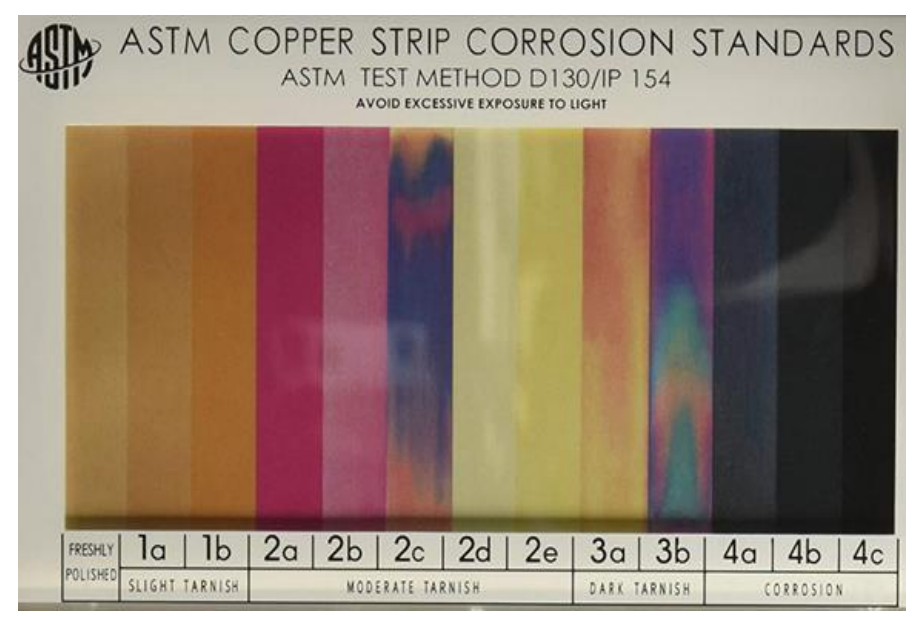

Figure 1. Copper strip corrosion standard based on ASTM D 130/IP 154. 
In order to realize a highly precise corrosion test method, we proposed the use of a quantitative-based thin-film technology [14]. The thin-film copper strips generate resistance values relative to the level of oil corrosiveness. These thin-film technology-based sacrificial copper strips serve as a reliable sensor to track the progression of sulfur corrosion, especially the corrosive by-products that are generated due to degradation in DBDS. The features of the sensors in relation to corrosion of sulfur at varying temperatures were investigated in [15], and further reported that the chemical reaction rate between the corrosive by-products due to degradation of DBDS and thin-film copper was dependent on temperature. However, solely detecting DBDS does not solve issues linked with sulfur corrosion due to presence of other sulfur compounds (i.e., mercaptans, elemental sulfur, and organic sulfides) that induce sulfur corrosion. In order to completely cover the sulfur corrosion paradigm, the proposed method enables two-fold contributions; first, the development of a new test to track one of the corrosive sulfur species, namely elemental sulfur and second, a regression model that estimates the transformation resistance values of the sensors as a function of area and thickness, which has been formulated and verified via two-level $\left(2^{2}\right)$ factorial experimental design.

\section{Materials and methods}

\subsection{Sensors fabrication process}

The schematic diagram of the sensors (i.e. area: $800 \mathrm{~mm}^{2}$ ) is illustrated in Figure 2. The thin-film copper strip was prepared by evaporating pure copper (purity: 99.99\%) onto a rectangular microscope glass substrate with an area of $1875 \mathrm{~mm}^{2}$. Pre-cleaning of the glass substrate was first carried out using acetone and isopropyl alcohol, followed by deionized water rinse, and finally, blow-dried with nitrogen. The evaporation was conducted by using a BOC Edwards E500a e-beam evaporator at a vacuum of $10^{-6} \mathrm{mBar}$ in nitrogen condition. In improving thin-film copper adhesion on glass substrate, a 5-nm thick titanium layer was 
evaporated prior to copper evaporation. Additionally, an aluminum shadow mask was used to obtain a constant desired area of the sensors, as detailed in Tables 2 and 3, respectively.

scale: $20 \mathrm{~mm}$

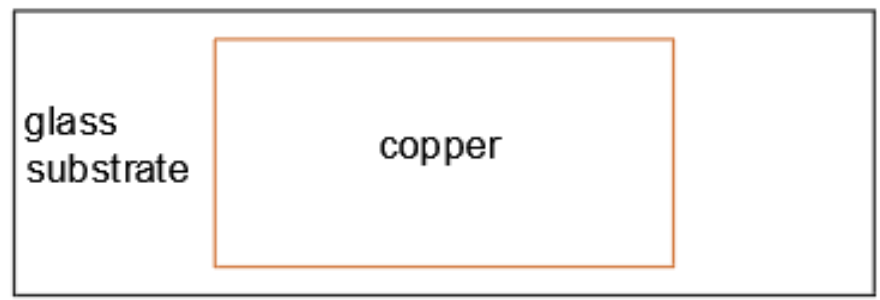

Figure 2. Schematic diagram of the sensors (top view). The thicknesses of copper are presented in Table 2.

\subsection{Two-level $\left(2^{2}\right)$ factorial design of experiment for screening purpose}

One-factor-at-a-time (OFAT) refers to a conventional method for designing experiments that involve testing of variables by changing one variable while retaining the rest at fixed condition. Despite of its ease in implementation, this technique appears to be ineffective in running multiple variables simultaneously. Due to this reason, design of experiments (DoE) has been weighed in as a suitable approach for multi-variable experiments as it significantly eases the number of test runs and ultimately saves manufacturing time and cost. There are the main reasons for DoE to be applied extensively in the fabricating and manufacturing domains.

A number of techniques are available to assess the correlations between a primary aspect and other interaction factors in experiments that embed multiple factors, for instance, response surface methodology (RSM) [16] and factorial design, as well as Taguchi method [17] and mixture design. In this study, the $2^{2}$ factorial design of experiment had been selected due to its capability in formulating the regression model that predicts transformation resistance values of the sensors as a function of area and thickness. This regression model can be verified statistically via analysis of variance (ANOVA). 
The $2^{2}$ factorial design of experiment had been performed using Design Expert software version 10.0 (Stat-Ease, Inc., Minneapolis, USA). A screening process was carried out to analyze the significant effect of two independent variables with three repetitions for each test run on the resistance values of the sensors. The $2^{2}$ factorial design matrix was used to screen the variables that consisted of 12 test runs (see Table 3 ). Table 2 presents the level of factors, whereby minimum and maximum are designated as -1 and +1 , respectively. The measurements of resistance values of the sensors were conducted by adhering to the $2^{2}$ factorial design matrix. The electrical resistance exhibited by the sensors was measured via 4-wire measurement method in a Temperature and Humidity Controlled Environmental Room with temperature fixed at $20 \pm 0.5^{\circ} \mathrm{C}$. The advantages of this method in low resistance measurement have been listed in a prior study [14]. The effects of area and thickness (variables 1 and 2) on the sensor's transformation resistance values were determined by using a half-normal graph and an effect list, respectively.

Next, a regression model was built to estimate transformation resistance values exerted by sensors as function of thickness and area. Both statistical significance and sufficiency of the regression model were assessed using ANOVA. The outcomes retrieved from $2^{2}$ factorial design of experiments determined the fit of the regression model, which contained coefficients (multiplied by related factor levels), as follows:

$$
Y=\beta_{0}+\beta_{1} x_{1}+\beta_{2} x_{2}+\beta_{12} x_{1} x_{2}
$$

where $Y$ is response, $\beta_{n}$ represents coefficient associated with factor $n$, whereas $x_{1}$ and $x_{2}$ are variables that represent factors $A$ and $B$, respectively. Product $x_{1} x_{2}$ refers to interaction between individual factors. $\beta_{0}$ is model intercept, while $\beta_{1} x_{1}$ and $\beta_{2} x_{2}$ are individual effects of $x_{1}$ and $x_{2} \cdot \beta_{12} x_{1} x_{2}$ reflects two-factor interaction between $x_{1}$ and $x_{2}$. Next, regression analysis had been performed in units that were coded, while coefficients had been based on the 
coded units. After that, ANOVA was applied to obtain means squares (MS), coefficient of determination $\left(R^{2}\right)$, sum of squares $(S S)$, as well as $p$-values and $F$-values. Response surface plot was employed to visually identify the interaction between the factors that affected the sensor's transformation values. The linear regression model that described the correlations between the effect of both variables (area and thickness) and the transformation resistance values of the sensors were verified.

Table 2. Levels of mixing process parameters.

\begin{tabular}{|c|c|}
\hline $\begin{array}{c}\text { Factor } 1\left(\boldsymbol{A}: \text { Area }\left(\mathbf{m m}^{2}\right)\right) \\
\text { Type: Numeric }\end{array}$ & $\begin{array}{c}\text { Factor } 2(\text { B: } \text { Thickness }(\mathbf{n m})) \\
\text { Type: Numeric }\end{array}$ \\
\hline $100(-1)$ & $50(-1)$ \\
\hline $800(+1)$ & $70(+1)$ \\
\hline
\end{tabular}

Table 3. Factorial design matrix used for factors screening.

\begin{tabular}{|c|c|c|}
\hline \multirow{2}{*}{ Test run } & \multicolumn{2}{|c|}{ Variable code } \\
\cline { 2 - 3 } & A: Area $\left(\mathbf{m m}^{\mathbf{2}}\right)$ & B: Thickness $(\mathbf{n m})$ \\
\hline 1 & +1 & -1 \\
\hline 2 & +1 & -1 \\
\hline 3 & +1 & -1 \\
\hline 4 & -1 & +1 \\
\hline 5 & +1 & +1 \\
\hline 6 & -1 & +1 \\
\hline 7 & -1 & -1 \\
\hline 8 & -1 & -1 \\
\hline 9 & +1 & +1 \\
\hline 10 & -1 & +1 \\
\hline 11 & +1 & +1 \\
\hline 12 & -1 & -1 \\
\hline
\end{tabular}

\subsection{Preparation of corrosive oil and experimental procedures}

The corrosive oil samples were prepared using Nytro Gemini X mineral oil (courtesy of Nynas AB, Sweden). Elemental sulfur (purity: 99.998\%, Sigma Aldrich) at three concentrations $(15,20$, and $25 \mathrm{ppm})$ had been selected for simulation of varying levels of corrosion. Oil samples without elemental sulfur were prepared as well to distinguish between 
corrosive and non-corrosive settings. Dilution based on weight had been used to prepare the solutions. Solvent was used to clean every beaker and later the beakers were dried at $105{ }^{\circ} \mathrm{C}$ for about $30 \mathrm{~min}$ to ensure that no moisture is retained. Next, the glass bottles were left to cool for about $10 \mathrm{~min}$ to room temperature. After that, the solutions (insulating oils mixed with elemental sulfur) had been stirred for $\sim 30$ mins until the yellowish elemental sulfur solid homogenously dissolved in the insulating oils using a hot plate magnetic stirrer. The temperature of the hot plate was fixed to $115 \pm 1{ }^{\circ} \mathrm{C}$ based on elemental sulfur melting point. The beaker was covered with aluminium foil during the mixing process to avoid excessive evaporation and contamination.

In the attempt of accessing feasibility of sensors in monitoring the progression of corrosive sulfur in insulating oil, a set of sensors with similar area of $800 \mathrm{~mm}^{2}$ and thickness of $50 \mathrm{~nm}$ was selected. The initial resistance displayed by the sensors had been $0.34 \pm 0.01 \Omega$. The laboratory experimental tests were conducted by immersing the sensors into glass Petri dishes that contained $30 \mathrm{~mL}$ of corrosive and non-corrosive oils. The Petri dishes were covered with another Petri dish in order to minimize evaporation of oil over the aging process time. In this study, the samples were aged in a fan-oven for $1 \mathrm{~h}$ at $90{ }^{\circ} \mathrm{C}$. Prior to measuring resistance, sensors were removed from the glass Petri dishes with clean pair of tweezers and further cleansing with solvent to discard oil residue on the surface of the sensors. Alteration in resistance because of sulfur corrosion caused by elemental sulfur was calculated as given in the following:

$$
\Delta R=R_{1}-R_{i}
$$

where $\Delta R$ refers to change sensor resistance values, $R_{l}$ stands for measured resistance values after 1 hour of aging, and $R_{i}$ is the measured initial resistance prior to aging. 


\section{Results and discussion}

\subsection{Screening factor experiment}

The $2^{2}$ factorial design, which was applied to screen the factor experiment outcomes in effect list and half-normal plot, is portrayed in Figure 3 and Table 4, respectively. Figure 3 illustrates that factors $A$ (area), $B$ (thickness), and $A-B$ interaction (area and thickness) are located away from the straight line. Besides, none of the variables coincide with the straight line. The plot that shows variables $A$ and $B$, as well as $A-B$ interaction, refers to significant model terms. These outputs are supported by the effect list, which pointed out that variable $A$ emerged as the most essential factor with $90.19 \%$ of contribution. The $S S$ of the variable is 2.78. This is followed by factor $B$ with $7.98 \%$ contribution and $S S$ of 0.25 . On the contrary, the $A-B$ interaction displayed a contribution of $0.14 \%$, which signified the least contribution of this particular factor amongst the rest. The $S S$ for $A-B$ interaction is 0.004 . From the outcomes, factor $A$ significantly contributes higher to transformation resistance values of the sensors, when compared to factor $B$ and $A-B$ interaction. It shall be noted that $1.69 \%$ of the contribution had been due to error.

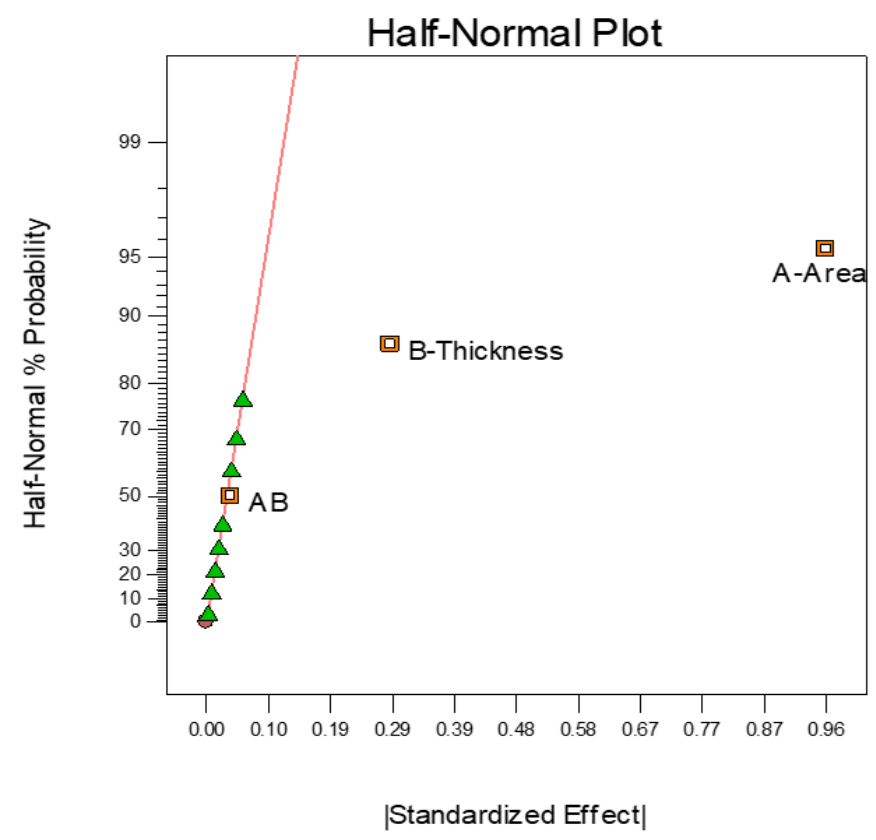

Figure 3. Half-normal plot for the screening factors. 
Table 4. Effect list of all model terms for the screening factor experiment.

\begin{tabular}{|c|c|c|c|}
\hline Model term & Standardized effects & Sum of squares, $S S$ & $\begin{array}{c}\text { Percentage contribution } \\
(\%)\end{array}$ \\
\hline$A$ & 0.96 & 2.78 & 90.19 \\
\hline$B$ & 0.29 & 0.25 & 7.98 \\
\hline$A-B$ interaction & 0.038 & 0.004 & 0.14 \\
\hline Error & & 0.052 & 1.69 \\
\hline
\end{tabular}

\subsection{Regression model}

A regression model based on the $2^{2}$ factorial design, which described the transformation resistance values of the sensors as a function of area and thickness, is presented in Equation (3).

$$
\frac{1}{\sqrt{R}}=1.38+0.48 x_{1}+0.14 x_{2}+0.019 x_{1} x_{2}
$$

In order to easily visualize the factors that affected the transformation resistance values of the sensors, the response surface plot was generated (see Figure 4). As observed from Figure 4, the transformation resistance values of the sensors increased gradually as the area was decreased from $800 \mathrm{~mm}^{2}$ to $100 \mathrm{~mm}^{2}$, while the thickness was reduced from $70 \mathrm{~nm}$ to $50 \mathrm{~nm}$. The prediction of transformation resistance values of the sensors presented in Table 5 have been based on the regression modeling using the regression equation (see Equation (3)). Table 5 shows that the highest residual between the measured and predicted value is $0.16 \Omega^{-\frac{1}{2}}$. 


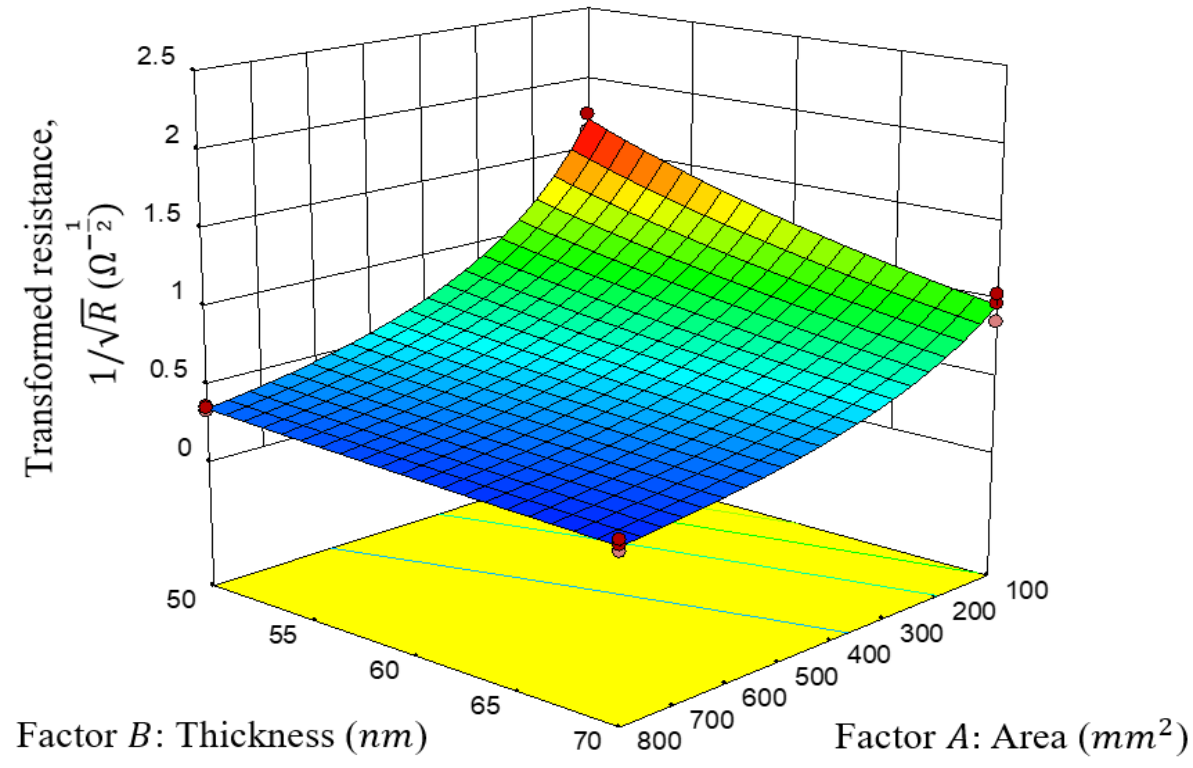

Figure 4. Response surface plot of transformation resistance values of the sensors vs. area and vs. thickness.

Table 5. Measured and predicted transformation resistance values of the sensors.

\begin{tabular}{|c|c|c|c|}
\hline $\begin{array}{c}\text { Test } \\
\text { run }\end{array}$ & $\begin{array}{c}\text { Measured } 1 / \sqrt{R} \text { value, } Y \\
\left(\Omega^{-\frac{1}{2}}\right)\end{array}$ & $\begin{array}{c}\text { Predicted } 1 / \sqrt{R} \text { value, } Y^{\prime} \\
\left(\Omega^{-\frac{1}{2}}\right)\end{array}$ & $\begin{array}{c}\text { Residual, } Y-Y^{\prime} \\
\left(\Omega^{-\frac{1}{2}}\right)\end{array}$ \\
\hline 1 & 1.69 & 1.70 & -0.01 \\
\hline 2 & 1.74 & 1.70 & 0.04 \\
\hline 3 & 1.67 & 1.70 & -0.03 \\
\hline 4 & 1.01 & 1.02 & -0.01 \\
\hline 5 & 2.18 & 2.02 & 0.16 \\
\hline 6 & 0.98 & 1.02 & -0.04 \\
\hline 7 & 0.76 & 0.77 & -0.02 \\
\hline 8 & 0.79 & 0.77 & 0.01 \\
\hline 9 & 2.00 & 2.02 & -0.02 \\
\hline 10 & 1.08 & 1.02 & 0.06 \\
\hline 11 & 1.89 & 2.02 & -0.13 \\
\hline 12 & 0.78 & 0.77 & 0.01 \\
\hline
\end{tabular}

The details of ANOVA outcomes for the factorial model are summarized in Table 6. The overall regression model seems to be statistically significant since the $p$-value is $<0.0001$ (below 0.05). In addition, the $p$-values for individual factors are below $0.05(<0.0001,0.0003$, and 0.4341 for Factors $A$ and $B$, as well as $A-B$ interaction, respectively). Hence, the regression model built in this research appears adequate as the value of $R^{2}$ is 0.9831 , signifying that the 
model can explain $98.31 \%$ of the total variation of the sensor's transformation resistance values because of variation in the independent variables (area and thickness).

Table 6. ANOVA results for the factorial model.

\begin{tabular}{|c|c|c|c|c|c|c|}
\hline Source & $\begin{array}{c}\text { Sum of } \\
\text { squares, } \\
S S\end{array}$ & $\begin{array}{c}\text { Degrees of } \\
\text { freedom, } \\
D f\end{array}$ & $\begin{array}{c}\text { Mean } \\
\text { square, } \\
M S\end{array}$ & $F$-value & $p$-value & $\begin{array}{c}\text { Coefficient of } \\
\text { determination, } \\
R^{2}\end{array}$ \\
\hline Model & 3.030 & 3 & 1.010 & 155.30 & $<0.0001$ & 0.9831 \\
\hline$A$ : Area & 2.780 & 1 & 2.780 & 427.38 & $<0.0001$ & \\
\hline$B$ : Thickness & 0.250 & 1 & 0.250 & 37.83 & 0.0003 & \\
\hline $\begin{array}{c}A-B \\
\text { Interaction }\end{array}$ & 0.004 & 1 & 0.004 & 0.68 & 0.4341 & \\
\hline Pure error & 0.052 & 8 & 0.007 & & & \\
\hline $\begin{array}{c}\text { Corrected } \\
\text { total sum of } \\
\text { squares }\end{array}$ & 3.080 & 11 & & & & \\
\hline
\end{tabular}

\subsection{Model verification}

In order to validate the regression model presented in Equation (3), three additional sensors (area: $300 \mathrm{~mm}^{2}-800 \mathrm{~mm}^{2}$; thickness: $60 \mathrm{~nm}-70 \mathrm{~nm}$ ) were fabricated. The measured $1 / \sqrt{R}$ values of the sensors were obtained by measuring their resistance, while the predicted $1 / \sqrt{R}$ values of the sensors were calculated using Equation (3). The predicted values were compared with the measured values, as tabulated in Table 7 . The average percentage variance between the measured and predicted values is $5.80 \%$. The root mean square error (RMSE) between the actual value, $\hat{y}$, and the predicted value, $y$, was obtained using:

$$
R M S E=\sqrt{\frac{1}{n} \sum_{i=1}^{n}\left(\hat{y}_{i}-y_{i}\right)^{2}}
$$

The RMSE for the three sensor samples is 0.1079 . This value is higher than the regression model as it was determined from only three samples. The accuracy of the RMSE can be increased by having larger sample population. 
Table 7. Comparison between the measured and predicted $1 / \sqrt{R}$ of 3 new sensors for verification.

\begin{tabular}{|c|c|c|c|c|c|}
\hline Sample & $\begin{array}{c}\text { Area } \\
\left(\mathrm{mm}^{2}\right)\end{array}$ & $\begin{array}{l}\text { Thickness } \\
\text { (nm) }\end{array}$ & $\begin{array}{c}\text { Measured } 1 / \sqrt{R} \\
\text { value } \\
\left(\Omega^{-\frac{1}{2}}\right) \\
\end{array}$ & $\begin{array}{c}\text { Predicted } 1 / \sqrt{R} \\
\text { value } \\
\left(\Omega^{-\frac{1}{2}}\right)\end{array}$ & $\begin{array}{c}\text { Percentage } \\
\text { difference } \\
(\%)\end{array}$ \\
\hline 1 & 300 & 70 & 1.43 & 1.31 & 8.39 \\
\hline 2 & 450 & 70 & 1.49 & 1.52 & 2.01 \\
\hline 3 & 800 & 60 & 2.00 & 1.86 & 7.00 \\
\hline
\end{tabular}

\subsection{Thin-film sacrificial copper strips as sulfur corrosion sensors}

The addition of elemental sulfur into insulating oils at varied concentrations produced varying corrosion settings. Figure 5 shows that incremental change in elemental sulfur concentrations leads to increased loss of copper from glass substrate, hence modified the sensor surface morphology. After $1 \mathrm{~h}$ of aging at $90^{\circ} \mathrm{C}$ in the presence of oxygen, the sensor surface aged in non-corrosive $(0 \mathrm{ppm})$ oil remained unchanged. This indicates that the occurrence of sulfur corrosion is impossible due to absence of elemental sulfur in the insulating oil. Figure 5 shows that the quantity of copper loss is higher with increased concentration of elemental sulfur (25 ppm), thus causing corrosion of almost all of the copper. It is relatively challenging to distinguish between the sensors aged in $15 \mathrm{ppm}$ and $20 \mathrm{ppm}$ of elemental sulfur. Therefore, a low resistance measurement method is proposed in this study to assess the feasibility of this method in measuring resistance values of the sensors. 


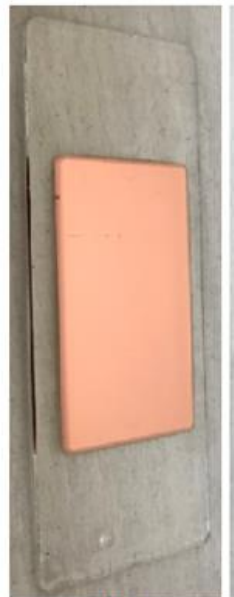

(a)

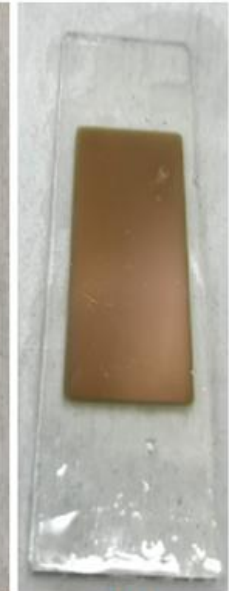

(b)

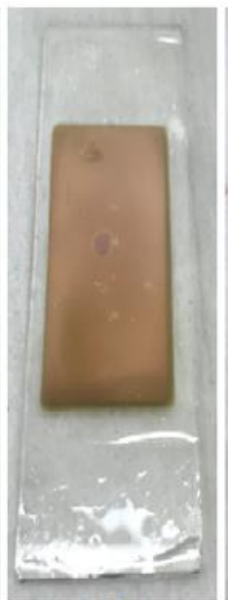

(c)

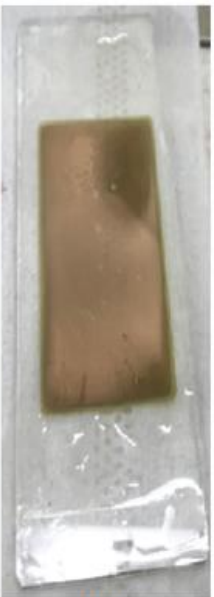

(d)

Figure 5. Surface morphology of $50 \mathrm{~nm}$ thin film copper strips aged at $90{ }^{\circ} \mathrm{C}$ in different elemental sulfur concentrations: (a) 0 ppm, (b) $15 \mathrm{ppm}$, (c) $20 \mathrm{ppm}$, and (d) $25 \mathrm{ppm}$.

Based on theory, the escalating changes in sensor resistance $(\Delta R)$ is linked with the decreasing amount of copper from glass substrate. In order to verify this theory, resistance was measured with a digital micro-ohmmeter (Megger Ducter ${ }^{\mathrm{TM}}$ DLRO-10X, Megger Ltd., UK). Figure 6 displays the variation in $\Delta R$, which serves as a function of elemental sulfur concentrations. The $\Delta R$ increases from $0.00 \Omega$ to $8.08 \Omega$, with increment in elemental sulfur concentrations from $0 \mathrm{ppm}$ to $25 \mathrm{ppm}$. This increase suggests a decreasing amount of copper from the glass substrate, as observed from Figure 5. This finding demonstrates that increments in elemental sulfur concentration enhances the process of sulfur corrosion. In general, the value of $\Delta R$ aged in non-corrosive oil ( $0 \mathrm{ppm}$ of elemental sulfur) remained unchanged. The elemental sulfur began attacking the surface of copper at low concentration (15 ppm), whereby $\Delta R$ increased from $0.00 \Omega$ to $0.48 \Omega$. Figure 6 illustrates that loss of copper from glass substrate had been higher with increased concentration of elemental sulfur ( $20 \mathrm{ppm})$, when compared to $15 \mathrm{ppm}$ that led to rapid corrosion of thin-film copper strip and slight increment in the value of $\Delta R$. Meanwhile, the value of $\Delta R$ aged in $25 \mathrm{ppm}$ of elemental sulfur increased rapidly to $8.08 \Omega$ as almost all the copper had corroded. Hence, it can be deduced that the experimental results 
offer evidence that the elemental sulfur plays a vital role in creating a corrosive environment on the copper surface in power transformers.

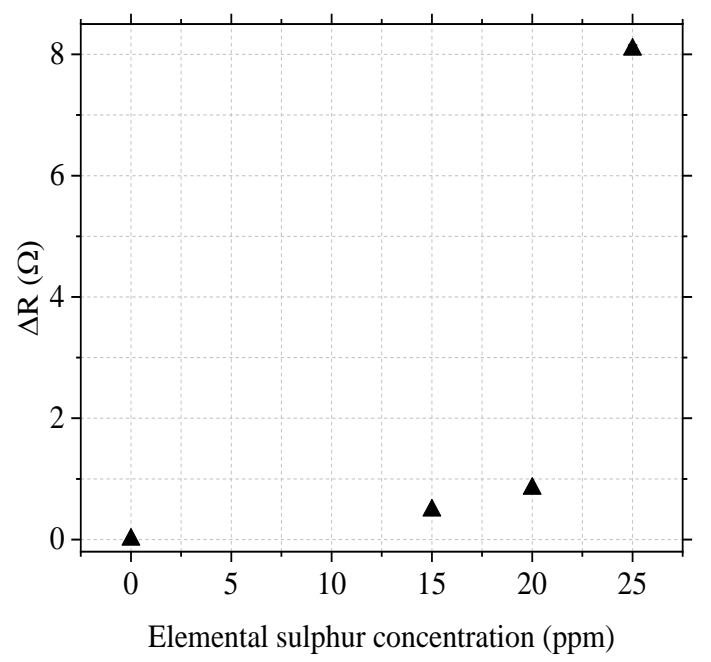

Figure 6. $\Delta R$ of the sensors aged in (a) $0 \mathrm{ppm}$, (b) $15 \mathrm{ppm}$, (c) $20 \mathrm{ppm}$, and (c) $25 \mathrm{ppm}$ of elemental sulfur.

\section{Conclusion}

This paper presents evidence that the $2^{2}$ factorial design is indeed a useful method to assess the significant effect of two independent variables on transformation resistance values of sacrificial copper strip sensors. This technique decreases sensor fabricating time and costs as it only requires a small number of test runs, in comparison to those demanded in the OFAT method. Besides, the outputs retrieved from $2^{2}$ factorial design revealed that the sensor area has greatest impact on the sensor's transformation resistance values gave $90.19 \%$ contribution. A regression model that describes the correlation between two independent variables (area and thickness) and transformation resistance values of the sensors has been developed. It can be concluded that the model is acceptable in predicting the transformation resistance values of the sensors as a function of area and thickness, whereby $R^{2}$ and $p$-value of the model are 0.9831 and $<0.0001$, respectively. The regression model generated in this study is remarkably exceptional with an RMSE of 0.1079. The experimental outcomes revealed that the proposed 
thin-film sacrificial copper strips are indeed feasible in monitoring progress of sulfur corrosion in oil-immersed power transformers via 4-wire measurement technique.

\section{Acknowledgment}

The first author gratefully acknowledges the financial support extended by Malaysia's Ministry of Education and University Teknikal Malaysia Melaka (UTeM) during his PhD study. The author also would like to express his gratitude to the Integrated Photonics Cleanroom, Optoelectronics Research Centre, University of Southampton, for fabricating the sensors used in this study.

\section{References}

[1] J.M. Lukic, S.B. Milosavljevic, A.M. Orlovic, Degradation of the Insulating System of Power Transformers by Copper Sulfide Deposition: Influence of Oil Oxidation and Presence of Metal Passivator, Ind. Eng. Chem. Res. 49 (2010) 9600-9608. doi:10.1021/ie1013458.

[2] F. Scatiggio, V. Tumiatti, R. Maina, M. Tumiatti, M. Pompili, R. Bartnikas, Corrosive Sulfur Induced Failures in Oil-Filled Electrical Power Transformers and Shunt Reactors, IEEE Trans. Power Deliv. 24 (2009) 1240-1248. doi:10.1109/TPWRD.2008.2005369.

[3] F. Scatiggio, V. Tumiatti, R. Maina, M. Tumiatti, M. Pompili, R. Bartnikas, Corrosive Sulfur in Insulating Oils: Its Detection and Correlated Power Apparatus Failures, IEEE Trans. Power Deliv. 23 (2008) 508-509. doi:10.1109/TPWRD.2007.911121.

[4] L. R. Lewand, The Role of Corrosive Sulfur in Transformers and Transformer Oil, Doble Eng. Company, USA. (2002) 1-15. https://www.doble.com/wp-content/uploads/2002_3B.pdf.

[5] M.A. G. Martins, Experimental Study of the Thermal Stability of Irgamet 39 and Dibenzyl Disulfide in the Laboratory and in Transformers in Service, IEEE Electr. Insul. Mag. (2014) 28-33. doi:10.1109/MEI.2014.6843765.

[6] R. Maina, V. Tumiatti, M. Pompili, R. Bartnikas, Corrosive Sulfur Effects in Transformer Oils and Remedial Procedures, IEEE Trans. Dielectr. Electr. Insul. 16 (2009) 1655-1663. doi:10.1109/TDEI.2009.5361586.

[7] M.A. G. Martins, A. R. Gomes, Experimental Study of the Role Played by Dibenzyl Disulfide on Insulating Oil Corrosivity-Effect of Passivator Irgamet 39, IEEE Electr. Insul. Mag. 26 (2010) 27-32. doi:10.1109/MEI.2010.5511186

[8] L. R. Lewand, S. Reed, Destruction of Dibenzyl Disulfide in Transformer Oil, in: 75th Annu. Int. Doble Client Conf., 2008: pp. 120. https://www.doble.com/wp-content/uploads/2008-DBDS_Destruction_Lewand_and_Reed.pdf.

[9] M. Dahlund, I. Atanasova-Höhlein, R. Maina, N. Dominelli, T. Ohnstad, T. Amimoto, C. Claiborne, M.-H. Ese, J. Lukic, V. Mezhvynskiy, C. Perrier, P.Smith, J. Tanimura, CIGRE WG A2-32 Copper Sulphide in Transformer Insulation, Final Report, 2009.

[10] C. Bengtsson, M. Dahlund, J. Hajek, L.F. Pettersson, K. Gustafsson, R. Leandersson, A. Hjortsberg, Oil Corrosion and Conduction Cu2S Deposition in Power Transformer Windings, in: CIGRE, Tech. Rep. A2-111, 2006: pp. 1-10.

[11] R. Maina, V. Tumiatti, F. Scatiggio, M. Pompili, R. Bartnikas, Transformers Surveillance Following Corrosive Sulfur Remedial Procedures, IEEE Trans. Power Deliv. 26 (2011) 2391-2397. doi:10.1109/TPWRD.2011.2157177.

[12] F. Scatiggio, M. Pompili, R. Bartnikas, Effects of Metal Deactivator Concentration upon the Gassing Characteristics of Transformer Oils, IEEE Trans. Dielectr. Electr. Insul. 18 (2011) 701-706. doi:10.1109/TDEI.2011.5931055. 
[13] ASTM D1275-06, Standard Test Method for Corrosive Sulfur in Insulating Oils, 1998.

[14] M.S. Ahmad Khiar, R.C.D. Brown, P.L. Lewin, Tracking the Progression of Sulfur Corrosion in Transformer Oil Using Thin Film Sacrificial Copper Strip, in: IEEE 2nd Int. Conf. Dielectr., IEEE, 2018: pp. 8-11. doi:10.1109/ICD.2018.8514715.

[15] M.S.A. Khiar, R.C.D. Brown, P.L. Lewin, Effect of Temperature Changes on Tine Film Sacrificial Copper Strips due to Sulfur Corrosion, in: Annu. Rep. - Conf. Electr. Insul. Dielectr. Phenomena, CEIDP, 2018 : pp. 490-493. doi:10.1109/CEIDP.2018.8544883.

[16] S.A. Ghani, N.A. Muhamad, H. Zainuddin, Z.A. Noorden, N. Mohamad, Application of response surface methodology for optimizing the oxidative stability of natural ester oil using mixed antioxidants, IEEE Trans. Dielectr. Electr. Insul. 24 (2017) 974983. doi:10.1109/TDEI.2017.006221.

[17] S.A. Ghani, N.A. Muhamad, Z.A. Noorden, H. Zainuddin, A.A. Ahmad, Multi-response optimization of the properties of natural ester oil with mixed antioxidants using taguchi-based methodology, IEEE Trans. Dielectr. Electr. Insul. 24 (2017) 1674-1684. doi:10.1109/TDEI.2017.006589. 